\title{
- CINTED-UFRGS Novas Tecnologias na Educação \\ O USO DO SOFTWARE COMUNIQUE COMO RECURSO TECNOLÓGICO NO PROCESSO DE ENSINO E APRENDIZAGEM DE ALUNO(S) COM PARALISIA CEREBRAL
}

\author{
Ramon Orlando Filho1 \\ Luciana Zenha2 \\ Anna Paula Matos Couto3 \\ Cacilda da Silva Rodrigue3 \\ Leila Alvarenga Lage3 \\ Sandra Aparecida Almeida3
}

1 - Estudante do Curso de Pedagogia da UEMG - Campus Belo Horizonte (UEMG/ FaE/ CBH) e Bolsista PRODOC/UFMG - Pesquisa: "O estado do conhecimento sobre a

Rede Municipal de Ensino de Belo Horizonte 1986-2005”. ramonrof@ gmail.com

2 -Professora Orientadora - Mestre em Educação/ Coordenadora CEPEAD/UEMG e Professora da Faculdade de Educação da UEMG.

3 - Estudantes do Curso de Pedagogia da UEMG - Campus Belo Horizonte (UEMG/ $\mathrm{FaE} / \mathrm{CBH})$

\section{Resumo}

O presente artigo tem como objetivo colaborar com subsídios teóricos para uma melhor compreensão de aspectos que envolvem a utilização do computador, do Software Comunique e das tecnologias assistivas na educação de pessoas com necessidades especiais. Abordaremos as consequiências da deficiência na limitação de pessoas dando um enfoque na possibilidade de melhoria na qualidade de vida por meio dos recursos tecnológicos e da tecnologia assistiva, visto que estes oferecem inúmeros instrumentos que possibilitam e/ ou facilitam a inclusão e execução de atividades que antes eram impossíveis de ser realizadas devido a limitação.

Palavras-chave: Computador, Software Comunique, Inclusão, Educação Especial.

\begin{abstract}
The present article has as objective to collaborate with theoretical subsidies for one better understanding of aspects that involve the use of the computer, of Software It communicates and of the assistivas technologies in the education of special people with necessities. We will approach the consequences of the deficiency in the limitation of people giving an approach in the possibility of improvement in the quality of life by means of the technological resources and of the assistiva technology, since these offer innumerable instruments that make possible and/or facilitate the inclusion and execution of activities that before were impossible to be carried through had the limitation.
\end{abstract}

Key words: Computer, Software Comunique, Inclusion, Special Education. 


\title{
Introdução
}

\begin{abstract}
"As crianças com deficiência (física, auditiva, visual ou mental) têm dificuldades que limitam sua capacidade de interagir com o mundo. Estas deficiências podem impedir que estas crianças desenvolvam habilidades que formam a base do seu processo de aprendizagem. Estas deficiências impedem também que elas executem atividades que podem ajudar aos educadores $e$ terapeutas entender e avaliar a capacidade intelectual de cada criança”. VALENTE, 1991: 01.
\end{abstract}

A proposta de pesquisa e o propósito desse artigo é refletir sobre as limitações das pessoas com deficiência - foco em paralisia cerebral e se esse tipo de dificuldade impede ou reduz a habilidade, possibilidade e capacidade das mesmas de exercer determinada atividade, ou hipótese estudada é se a tecnologia pode oferecer instrumentos que minimizem as limitações ou possibilita a estas pessoas de ter uma vida mais independente e/ou realizar atividades que antes lhes era impossível.

A fala constitui um elemento fundamental na comunicação e no desenvolvimento da linguagem na medida em que possibilita ao indivíduo maior independência. Nesse contexto o indivíduo com paralisia cerebral, que apresenta comprometimentos na fala, ou uma fala não funcional, fica em situação de dependência de outros para realizar até mesmo as atividades mais simples, o que compromete profundamente sua autonomia.

Segundo Romeu Sassaki a assistive technology (tecnologia assistiva) é um termo que tem sido utilizado frequientemente para se referir

\footnotetext{
"a tecnologia destinada a dar suporte (mecânico, elétrico, eletrônico, computadorizado etc.) a pessoas com deficiência física, visual, auditiva, mental ou múltipla. Esses suportes, então, podem ser uma cadeira de rodas de todos os tipos, uma prótese, uma órtese, uma série infindável de adaptações, aparelhos e equipamentos nas mais diversas áreas de necessidade pessoal (comunicação, alimentação, mobilidade, transporte, educação, lazer, esporte, trabalho e outras)". SASSAKI, 1996.
}

A tecnologia assistiva é composta por recursos e serviços. Os recursos compreendem os equipamentos ou parte deles, os sistemas fabricados em série ou sob-medida que são utilizados para possibilitar ou aumentar as capacidades funcionais das pessoas com deficiência. Já os serviços são os recursos que auxiliam a pessoa com deficiência a selecionar, comprar ou usar os recursos acima definidos.

O objetivo primordial da Tecnologia Assistiva é propriciar as pessoas com necessidades especiais maior independência, melhoria na qualidade de vida e inclusão social, por meio da ampliação das possibilidades de sua comunicação, mobilidade e/ ou aprendizagem.

\footnotetext{
“A Tecnologia Assistiva engloba áreas como a comunicação suplementar e/ ou alternativa, as adaptações de acesso ao computador; equipamentos de auxílio para visão e audição; controle do meio ambiente; adaptação de jogos e brincadeiras, adaptações de postura sentada, mobilidade alternativa, próteses e a integaração dessa tecnologia nos diferentes ambientes como a casa, escola e local de trabalho". KING, 1999.
} 
$\mathrm{O}$ acesso e uso do computador está intrinsecamente ligado a habilidade motora que o aluno possui devido aos agravantes da deficiência. As pessoas com necessidades educacionais especiais podem precisar de órteses, colméia, teclado expandido, tela sensível ao toque, acionadores externos e softwares educacionais especiais.

Há pessoas com necessidades especiais que não necessitam de recursos especiais que facilitem seu acesso ao computador, entretanto há outros que necessitam de adaptações seja em seu próprio corpo ou no computador.

\footnotetext{
"Estamos aprendendo a criar ambientes de aprendizagem não somente para sobrepujar a deficiência cognitiva, mas para mudar uma situação sem esperança em algo mais promissor. $\mathrm{O}$ fato de estarmos ajudando os deficientes a liberarem suas mentes nos propiciarão meios para ver que por detrás da luta que estas pessoas realizam para interagir com o mundo existe um ser humano que deseja fazer coisas, melhorar, e de ser independente". VALENTE, 1991: 04.
}

Nesse contexto, percebe-se que o computador é uma importante ferramenta a ser utilizada nesse processo de ensino e aprendizagem na medida em que auxilia o processo de resolução de problemas e torna possível a manipulação de conceitos envolvidos nos problemas sendo resolvidos e dessa forma propicia meios para o aprendizado desses conceitos.

Piaget propõe a idéia de que as crianças têm capacidade de construir seu próprio conhecimento, entretanto o ritmo de aprendizagem depende das ferramentas que são dispostas para as crianças, dos métodos de ensino e da interação com a cultura na qual vivem. Se o ambiente não qual a criança vive não é suficiente para fazer com que ela aprenda é necessário fornecer ferramentas e criar ambientes de aprendizagem. Com portadores de necessidades especiais a criação desses ambientes é fundamental, visto que o organismo dos mesmos é deficiente em algumas funções.

\footnotetext{
"O computador é o instrumento que ajuda a minimizar as barreiras entre a criança e o mundo físico movendo os objetos, realizando o desenho ou a escrita. Ao invés de solicitar que o professor ou auxiliar execute a atividade, a criança deve comandar o computador para que este realize a tarefa. Assim a criança consegue apertar uma tecla, ela pode comandar o computador para fazer praticamente tudo o que ela deseja, sem precisar pedir as outras pessoas, e sem ser limitada pela sua dificuldade de se comunicar com o mundo das pessoas e dos objetos". VALENTE, 1991: 06.
}

O computador ao fornecer ambientes de aprendizagem tem auxiliado na educação de alunos com necessidades especiais na medida em que oferece novos caminhos possíveis de aprendizagem para a criança, visto que não limita seu potencial e restringe sua capacidade como ocorre freqüentemente.

\section{O Software Comunique}

O software é gratuito e apresenta a possibilidade de ser inserido no computador através da Internet ou por cópia em Cdrom. Desenvolvido por uma Terapeuta Ocupacional, Miryam Bonadiu Pelosi tendo como objetivo trabalhar a comunicação alternativa oral e escrita de pessoas com necessidades especiais que apresentam problemas motores 
graves, alfabetizadas ou em processo de alfabetização.Atualmente, o computador e o software Comunique trata de um importante recurso experimental e tecnológico a ser utilizado por pessoas com Paralisia Cerebral.

\begin{abstract}
"A tecnologia, mais especificamente a Tecnologia Assistiva, não é uma descoberta recente do homem. As pessoas nas mais diferentes culturas através da história criaram adaptações e utilizaram ferramentas especiais e equipamentos para ajudar as pessoas com necessidades especiais em suas sociedades" KING,1999.
\end{abstract}

A paralisia cerebral é definida como uma dificuldade de controle neuromotor ocasionada devido a uma lesão ocorrida em diferentes estruturas do encéfalo, antes que o cérebro amadureça por completo.

O termo paralisia cerebral costuma se empregado atualmente, como uma denominação geral que engloba distúrbios muito diversos. Tais distúrbios têm em comum, o fato de significarem uma alteração ou perda do controle motor, secundaria a uma lesão encefálica, ocorrida na etapa pré-natal, ou durante a primeira infância, seja qual for o nível mental da criança lesionada. (BASIL, Carmem, 1995: 252.

A paralisa cerebral engloba diversos distúrbios e provoca alteração ou perda do controle motor, podendo ou não estar associada a outras perturbações, apresentando comprometimento mental, visual, auditivo, sensorial e cognitivo. A lesão que causa a paralisia cerebral pode ocorrer antes, durante ou após o nascimento, caracterizada por uma alteração provocada por uma lesão não progressiva do cérebro em desenvolvimento.

Há várias formas de caracterizar a paralisia cerebral, podendo ser classificada de acordo com os efeitos funcionais ou pela topografia corporal. Os efeitos funcionais afetam o tônus muscular e os quadros clínicos mais freqüentes são: espástica, atetóide e ataxia

Além da espasticidade, atetóide e ataxia, ocorrem também alguns efeitos funcionais menos freqüentes como, rigidez e tremores. Os efeitos funcionais raramente ocorrem isolados e normalmente o individuo com paralisia cerebral apresenta quadros mistos e associados, representando, representando uma associação da forma atetósica com espástica, atáxica com espástica e outros.

De acordo com a topografia corporal, a alteração motora pode ser classificada como: paraplegia, tetraplégia, monoplegia, diplegia, triplegia e hemiplegia.

A paralisia cerebral não deve ser considerada como uma doença, visto que compreende uma lesão irreversível e não evolutiva do encéfalo, não podendo ser curada. Entretanto, a atenção, reabilitação física, educação, adaptações e intervenções adequadas e eficazes, podem melhorar significativamente a capacidade funcional de indivíduos com paralisia cerebral. O computador tornou-se uma ferramenta auxiliar de comunicação para as pessoas com comprometimentos nos órgãos da fala e com dificuldades motoras.

O Comunique é uma forma de possibilitar a pessoa com Paralisia Cerebral, obter uma interação social satisfatória. A expressão de seus sentimentos, desejos e necessidades se tornam mais compreensíveis, através de um programa de comunicação alternativa. 
Inicialmente o Comunique era um programa de comunicação muito simples, mesmo após algumas reformulações o Cominiq Desenho, apresentou-se ainda insuficiente para atender as necessidades de comunicação de seus usuários. $\mathrm{O}$ fato de $\mathrm{o}$ atendimento ser a indivíduos de diferentes idades, houve pessoas que apresentavam dificuldades para manusear com as seis informações presentes na tela, enquanto outras, as consideravam extremamente pequena e limitada.

Posteriormente criou-se o Comuniq Scan, ainda na versão DOS. Agora, no Software era possível trabalhar com letras e palavras. O numero de células, o tamanho e o tipo de letra podem ser facilmente modificados. O escaneamento pode ser realizado da seguinte forma: varredura; por linhas ou colunas ou pelo método tradicional de célula por célula. Já na programação, por manter o editor de textos não foi possível trabalhar com a manipulação de imagens.

A versão atual utilizou para o seu desenvolvimento, o programa Visual Basic que englobou o Comuniq Desenho e o Comuniq Scan. O Software Comunique foi desenvolvido na plataforma Windows 95 e sua programação pode ser realizada na própria tela com o uso da multimídia com CD-ROM e dos recursos audiovisuais e interativos do sistema operacional Windows.

O programa ainda funciona através do sistema de varredura das informações escritas na tela (símbolos, letras, sílabas, palavras ou frases). A varredura é feita por meio do escaneamento: Linha /Coluna, Movimento de setas, Clique do Mouse ou Célula por Célula.

O Comunique permite ao profissional que acompanha o individuo com paralisia cerebral, traumatismo craniano, lesão medular ou acidente vascular cerebral desenvolver um programa personalizado, a fim de atender as especificidades, interesses e necessidades de seus usuários. Visto que, os mesmos podem apresentar dificuldades motoras graves com

potencial de comunicação, cognição, visual e motor diversificados.

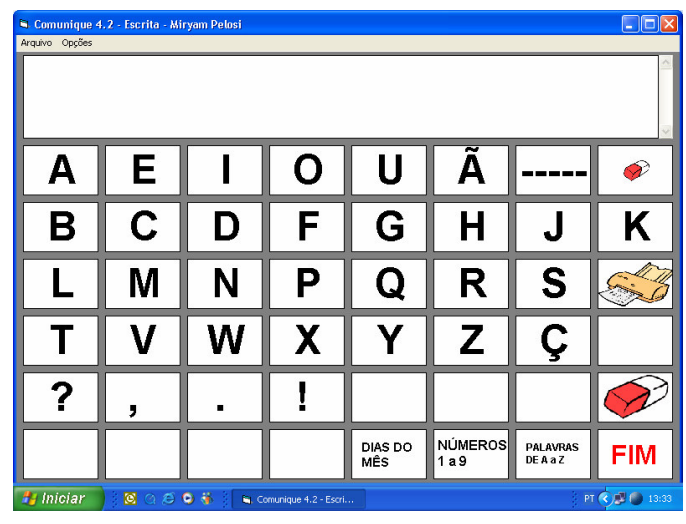

Comunique - Tela para escrita

O software também possibilita diferentes alternativas de acesso, seja por meio do uso dos periféricos presentes no próprio computador como: teclado, mouse adaptado, joystick ou através de recursos mais sofisticados como: tela sensível ao toque ou acionadores externos de pressão, tração, sopro, voz e outros.

O acionamento pode ser realizado por diferentes partes do corpo: cabeça, braço, mão, perna, pé, boca, olhos, etc. A escolha do tipo de acionamento, leva em consideração a condição motora da pessoa e o seu movimento mais voluntário.

Já o acionador externo (SWITCH), refere-se a um dispositivo que é acoplado no Joystich adaptado para possibilitar a pessoa com dificuldades motoras ter acesso ao Software Comunique. 
O Comunique disponibiliza de uma a sessenta e quatro células e uma a oito linhas ou colunas que são ajustadas de acordo com o numero de informações a serem disponibilizadas para cada pessoa. Os símbolos podem ser organizados em apenas uma tela ou mais, caso a pessoa apresente autonomia para navegar entre elas.

A velocidade de escaneamento varia de 0,1 a 20 segundos, o mesmo deve ser ajustado de acordo com a possibilidade de acompanhamento visual e motora da pessoa com Paralisia cerebral.

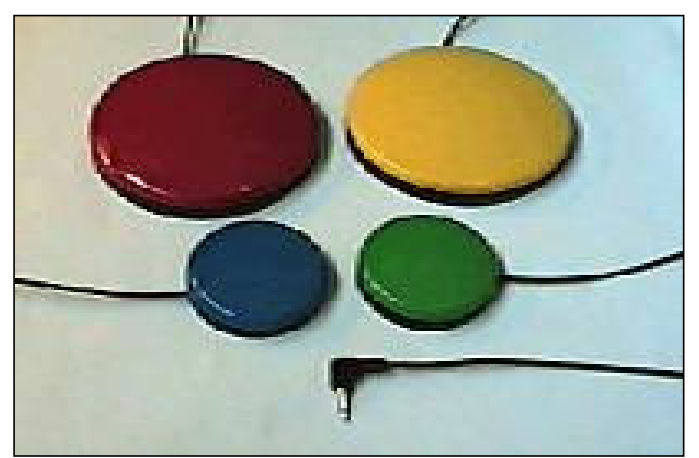

Mouse adaptado - acionador
O tempo de espera é um dos recursos disponíveis neste software, pois ele é utilizado quando a pessoa possui pouca coordenação motora, o que a faz aperta o acionador várias vezes em uma mesma tentativa. Então, este tempo de espera é um tempo programado no Software para aceitar um novo comando.

O teclado expandido é utilizado quando o profissional considera a coordenação motora da pessoa que acompanha insuficiente.

O tamanho, o tipo de letra e o controle da velocidade, a cor do visor, a presença ou não de imagens, a cor da célula são variáveis. A construção da tela em alto contraste trata-se de um requisito indispensável no momento da sua elaboração. Estes pequenos ajustes é que facilitam a compreensão e melhor visualização das informações disponíveis na tela.

O Comunique também possui o recurso de jogos que podem ser programados para cada pessoa e aumentar o nível de complexidade.

O baixo desenvolvimento intelectual da criança deficiente é algumas vezes justificado pela super proteção que elas recebem de pessoas que lidam com elas. Esse comportamento desobriga a criança de pensar e buscar autonomamente alternativas para suas necessidades e questões propostas, tendo em vista que sempre haverá alguém que pense e faça tudo por ela.

A ajuda excessiva é outro problema que atrapalha o desenvolvimento da criança deficiente, visto que não saberá o quanto deve esforçar-se para mover seu corpo, pensar até fazê-lo e se for sempre ajudada a fazer tudo o que deseja perderá a oportunidade de construir a autonomia e a auto realização de ter domínio sobre seu corpo, pensamento e adquire satisfação pessoal.

Não se deve fazer as atividades para a criança, mas criar ambientes de aprendizagem que disponham de ferramentas adaptadas as necessidades de cada criança deficiente nos quais ela consiga fazer as atividades que elas desejam fazer.

O termo "sociedade da informação" vem se construindo como um novo paradigma técnico-econômico, no qual a informação passa a ter um valor nunca antes alcançado. A convergência das tecnologias faz com que a informática e seus recursos, os meios de 


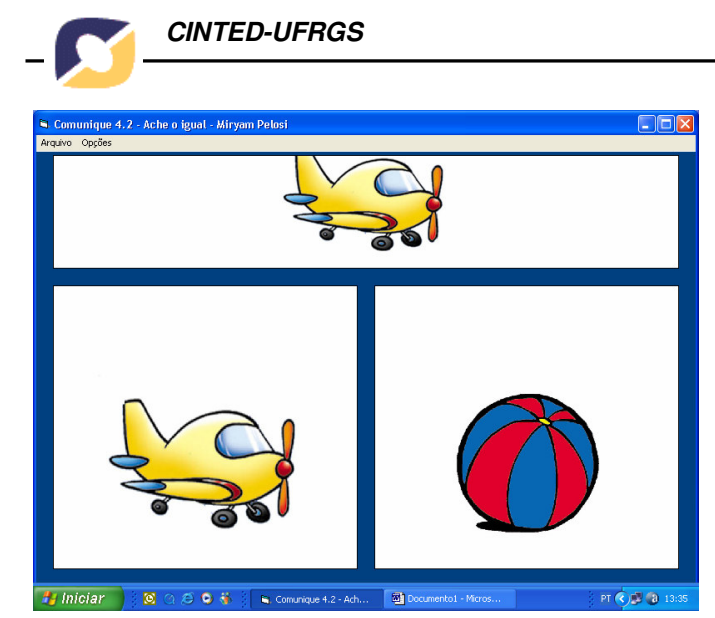

Jogo - Ache o igual.

comunicação e informação atinjam grande circulação possibilitando uma transmissão de informações e dados com uma precisão e velocidade cada vez maiores. Portanto, não existem fronteiras para as informações digitais.

O processo de criação de tecnologias é ininterrupto. A cada dia percebe-se um avanço nas tecnologias. O sistema de redes, por exemplo, permite a interatividade e transmissão de informações em tempo real.

Segundo Maturana deve-se uma resposta ao que é educar, afirmando que "sem aceitaçãoe respeito por si mesmo não se pode aceitar e respeitar o outro, e sem aceitar o outro como legítimo na convivência, não há fenômeno social" p.184. A Internet e a cibercultura precisam da aceitação do outro, pois reúnem pessoas de diferentes locais que compartilham virtualmente, um espaço de busca de interesses e objetivos. Esse fenômeno virtual interativo está em expansão, a partir dele tem-se uma possibilidade de nos educarmos mutuamente tendo em vista que a presença do outro é necessária, a exemplo dos fóruns de discussão e dos chats.

O avanço das tecnologias disponibilizou inúmeras ferramentas de transmissão da informação, entretanto há de se analisar o acesso restrito que a mesma possibilita devido à exclusão digital estar ligada diretamente à desigualdade social "uma camada on-line e um proletariado off-line". necessita-se de mudanças que viabilizem o acesso democrático e includente respeitando a diversidade e às singularidades.

Não é necessário todos andarmos um dia de cadeiras de rodas, ou estarmos aparentemente silenciados numa surdez. Não há que viver na diferença excluída para que possamos aprender a reconhecê-la e respeitá-la. ANDRADE, 2003: 185.

A igualdade, dentro de uma proposta de respeito à diversidade e heterogeneidade das deficiências e deficientes, tem de passar, além da inclusão escolar, por uma busca de equiparação social e econômica, através do trabalho, tendo como bases às políticas de ação afirmativa.

Para haver uma incorporação de novas técnicas e tecnologias na educação de portadores de necessidades especiais, ocasionando evolução e aprendizado significativo, deve-se ampliar a acessibilidade nos espaços escolares, utilizar desenhos universais (ícones), disponibilizar e socializar as tecnologias assistivas, bem como ajudas técnicas especializadas, formar e capacitar os educadores além de fundamentar estas ações com os recursos e materiais adequados às necessidades educacionais especiais e aos recursos financeiros aliados a políticas sociais e públicas.

\section{Material e Métodos}


A proposta dessa pesquisa é observar, através de estudo de caso de forma qualitativa, o processo de ensino e aprendizagem de aluno(s) com paralisia cerebral na Escola Brincar - Centro de Estimulação Especial auxiliado(s) pelo uso do software Comunique.

Serão utilizados como instrumentos: observação participante, entrevista semiestruturada a criadora do programa, professora que realiza o atendimento, diretora da Escola, análise documental do registro das atividades desenvolvidas pelos alunos ao longo da pesquisa e pesquisa bibliográfica.

A pesquisa qualitativa visa investigar os fenômenos histórico-estruturais e captar não só a aparência do fenômeno, mas sua essência. $\mathrm{Na}$ pesquisa qualitativa sendo essencialmente descritiva há intensa observação do ambiente, visto que o sujeito está envolto a situações de existência que possuem fundamental importância na construção da personalidade e determinam ou conduzem ações.

O estudo de caso reúne informações detalhadas, por meio de diferentes técnicas de pesquisa, com o objetivo de apreender a totalidade de uma situação e descrever a complexidade de um caso concreto. Através de um mergulho profundo e exaustivo em um objeto delimitado, o estudo de caso possibilita a penetração na realidade social, não conseguida pela estatística. GOLDENBERG: 2001.

\section{Considerações}

A paralisia cerebral não deve ser considerada como uma doença, visto que compreende uma lesão irreversível e não evolutiva do encéfalo, não podendo ser curada. Entretanto, a atenção, reabilitação física, educação, adaptações e intervenções adequadas e eficazes, podem melhorar significativamente a capacidade funcional de indivíduos com paralisia cerebral. O Software Comunique e as Tecnologias Assistivas poderão ser valiosos recursos na aprendizagem das pessoas com necessidades educacionais especiais.

\section{Referências}

ANDRADE, Jorge Márcio Pereira de. Para além das exclusões: por uma sociedade da informação rumo à sociedade do conhecimento e das diferenças. In SILVA, Shirley; VIZIM, Marly. Políticas públicas: educação, tecnologia e pessoas com deficiências. São Paulo: companhia das letras, 2003.

BASIL, Carmen. Os alunos com Paralisia Cerebral: desenvolvimento e educação. In: COLL, César; PALACIOS, Jesus; MARCHESI, Álvaro. Desenvolvimento psicológico e educação: necessidades educativas especiais e aprendizagem escolar. Porto Alegre: Artes Médicas, 1995. v. 3.

GOLDENBERG, Mirian. A arte de pesquisar: como fazer pesquisa qualitativa em ciências sociais. Rio de Janeiro: Record, 1997.

PAPERT, Seymour. A máquina das crianças: repensando a escola na era da informática. Porto Alegre: Artes Médicas, 1994. 
VALENTE, José Armando. Liberando a mente: computadores na educação especial. Campinas: Unicamp, 1991.

Aprendendo para a vida: o uso da informática na educação especial. In: FREIRE, Fernanda Maria Pereira; VALENTE, José Armando (Orgs.). Aprendendo para a vida: os computadores na sala de aula. São Paulo: Cortez, 2001.

Centro especializado em desenvolvimento infantil. Disponível em:

http://www.cedionline.com.br/ta.html, Acesso em 15 de novembro de 2006.

Cook e Hussey.Assistive Tecnologies: Principles and Pratice, Mosby-Year Book. Missouri, EUA, 1995.

KING, T. W. Assistive tecnology: essential human factors. Boston: Allyn and Bacon. 1999.

REILLY, Lucia. Escola inclusiva: linguagem e mediação. São Paulo: Papirus, 2002. 